\title{
Decentering and recentering the writing centre using online feedback: Towards a collaborative model of integrating academic literacies development ${ }^{1}$
}

\author{
Karen Suzette Collett \\ Department of Educational Studies, University of the Western Cape, South Africa \\ E-mail: kcollett@uwc.ac.za
}

Arona Dison

Directorate of Teaching and Learning, University of the Western Cape, South Africa

E-mail: adison@uwc.ac.za

\begin{abstract}
Since its inception in 1994, the University of the Western Cape's Writing Centre has been on the margins, viewed as an add-on to central learning and teaching activities at the university (Archer and Richards 2011, Clarence 2011). In this article, we use the constructs of place, space, and power to explore the decentering of feedback on students' writing from the face-to-face, physical location of the Centre to the formative assessment space in a module. We reflect on the Centre's engagement with a formative online feedback intervention conducted by a lecturer within a Bachelor of Education Honours course. Writing centre tutors participated in providing formative feedback on nested, scaffolded tasks leading to a long essay, using the feedback function of the Turnitin platform. The space of engagement with students moved from the faceto-face, physical writing centre location to the online space. We found that the development of the academic writing and feedback literacies of writing tutors, students, and the lecturer were developed through sustained and responsive online and face-to-face communities of praxis. In this process, there was a partial decentering and recentering of the role of the Centre, enabled by technology and the integration of the development of academic literacies within the course curriculum. The sustained engagement between the lecturer, tutors, and writing centre coordinator played an essential role in the effectiveness of the intervention. However, in order to further develop the feedback literacies of students, the online feedback needs to be complemented with additional face-to-face interaction. We argue for both a decentering and recentering of the role of writing centres towards supporting departments in the integration of academic literacies development into curricula. One of the ways of doing this is by using technology to expand capacity in order to give students feedback on their writing within a blended learning environment that focuses on formative assessment.
\end{abstract}

\footnotetext{
${ }^{1}$ We acknowledge the participation and contribution of the UWC Writing Centre tutors - Bernard Omukunyi, Freda Philander, Kenny Chiwarawara, Lebohang Mojapelo, Lovemore Kunorozva, Rasheeqa Waggie, Timalizge Zgambo, and Wenzokuhle Ncube - as well as the students of the B.Ed. Honours modules in 2018 and 2019.
} 
Keywords: writing centre; academic literacies; online feedback; formative assessment; feedback literacy

\section{Introduction}

Writing centres in South Africa have tended to be on the margins of the university, viewed as an add-on to central learning and teaching activities (Archer and Richards 2011). More recently, there have been shifts in thinking about the role of writing centres, and the need for them to become involved in collaborative work with lecturers in departments in order to facilitate processes of integrating academic literacies development into disciplinary curricula (Dison and Clarence 2017, Nichols 2017). The current model of the University of the Western Cape's (UWC) Writing Centre (henceforth, the Centre) is largely based on one-on-one consultations between tutors and students. The vision being shaped is for the Centre to increasingly play a role in supporting departmental strategies for overtly integrating the development of students' academic literacies into curricula without discarding the valuable work that has been taking place within the current model. We use the phrase "integration of the development of students' academic literacies" to mean the inclusion of explicit pedagogical strategies into disciplinary teaching and learning. In some places, we use the phrase "integration of academic literacies" as a shorthand for "integration of the development of students' academic literacies".

Student mass action in 2015, through the national \#Feesmustfall and \#Rhodesmustfall campaigns, clearly highlighted the needs of students at higher education institutions (HEIs) in South Africa for affordable, meaningful, flexible, and supportive higher education opportunities. Enhancing opportunities to support both student access and success in HEIs is critical to meeting both developmental needs and equity targets (Scott and Omar 2016, UWC 2015). These conditions present staff at writing centres with particular pedagogical and support challenges. One critical challenge is the need to improve systems of formative feedback to students in order to develop their academic writing in assessment tasks (Boud and Molloy 2013) while staff and tutors experience a heavy workload, particularly in modules where there are large classes. Carless and Boud (2018: 1) foreground the importance of developing students' feedback literacy, which they define as "the understandings, capacities and dispositions needed to make sense of information and use it to enhance work or learning strategies".

This article explores a case study of the Centre's involvement in supporting the development of students' academic literacies in a Bachelor of Education Honours (B.Ed. Honours) course in leadership and management. The lecturer designed the two modules with a series of nested assessment tasks, providing scaffolding for a long, argumentative essay. The students were given formative feedback at four points during the module, using the affordances of the feedback function of Turnitin, which is more commonly used as a plagiarism detection programme. Feedback was given by peers, the writing centre tutors, and the lecturer. We reflect on the use of an integrated and collaborative approach to the development of academic and feedback literacies through online and face-to-face communities of praxis. This approach involves a decentering and recentering of the roles of the writing centre, and student and lecturer support. 


\section{Background}

UWC has adopted an institutional approach to enhancing teaching and learning (Bozalek and Dison 2013), as reflected in the UWC Strategic Plan on Teaching and Learning (UWC Directorate of Teaching and Learning 2010), and in the current Institutional Operating Plan 2016-2020 (UWC 2015). An institutional approach is promoted by D'Andrea and Gosling (2005) who argue that in order to effect change, development of teaching and learning needs to be "embedded institutionally and directed at the entire staff' (Bozalek and Dison 2013). An important element of this teaching-and-learning policy was the formation of the UWC Charter of Graduate Attributes which envisaged students becoming "critically and relevantly literate [...] able to seek, discern, use and apply information effectively in a range of contexts" (UWC Directorate of Teaching and Learning 2010). The conception of graduate attributes was an enabling one where they are understood to be "at the heart of all scholarly learning and knowledge" (Barrie 2007: 440), and integrated into the curriculum. In addition, the UWC Assessment Policy (2012) emphasises formative assessment, recognising its powerful role in students' learning. Lecturers are required to take responsibility for alignment of the curricula, and the integration of graduate attributes - including academic literacies - into curricula. Most lecturers are subject specialists who do not have formal training in education. Thus they need to develop their knowledge and ability to explicitly integrate the development of students' graduate attributes. Teaching-andlearning specialists have been appointed in all of the faculties to work with lecturers, assisting them to integrate teaching-and-learning principles into their modules, to provide scaffolding for students, and embed graduate attributes into curricula.

The Centre was initiated in 1994 as part of the Academic Development Centre which aimed to assist students from disadvantaged schooling backgrounds, many of whom were speakers of English as an additional language (EAL; Leibowitz, Goodman, Hannon and Parkerson 1997). The aim was to provide students with epistemological access (Morrow 2009) to the forms of knowing and discourses of the university. The Centre provided services for a diverse range of students from different backgrounds, not only black EAL students. The current coordinator joined the Centre in 2017, before which there had been two years of inconsistent leadership and a subsequent lack of strategic direction. The Centre had been utilising a model based largely on individual consultations with students, where writing tutors held face-to-face consultations with individuals or groups of students about a draft of an essay or assignment. Tutors' engagement with the writing task was not contextualised in relation to the curriculum or, if the Centre was briefed on the task, it was a one-way interaction without dialogical engagement about the task. The Centre's work was largely housed in the physical writing centre building. In cases where students could not come into the Centre, they were offered the opportunity of what was called "online" feedback, where they sent a draft of an assignment via email, and received feedback from tutors using the MS Word Comment function.

The approach to teaching and learning at UWC, which is espoused in the Strategic Plan, is one in which practices aimed at enhancing students' learning need to be embedded in central educational practices in departments and faculties. However, there is a disconnect with the dominant model of the Centre in that its work takes place largely outside of the modules in which students are engaged. This is consistent with the historical, marginal role of writing centres in South African institutions. As Archer and Richards (2011) point out, the institutional placement of writing centres outside of faculties, and their lack of involvement in mainstream teaching and assessment lead these centres to be perceived as remedial. This model is based on 
a generic concept of 'academic literacy' (Archer and Richards 2011), according to which writing is seen as a vehicle to convey the content of what students are learning, rather than constituting central processes through which students learn and develop knowledge within deeply contextualised disciplines (Lea and Street 1998).

Writing in 2011, Sherran Clarence, then the coordinator of the Centre, argued for the Centre to develop a campus-wide, writing-across-the-curriculum approach "to encourage academic lecturers $[\ldots]$ to use writing for learning, evaluation and thinking in their classrooms, as well as in assessment" (Clarence 2011: 109). However, implementing such a model is not possible without buy-in, commitment, and resources from university management which did not share such a vision at that point. While there may be more openness to such a vision in the current context, the resources allocated remain unchanged.

\section{Integrating online writing centre feedback into an Education Honours course}

During 2018, Karen Collett, a senior lecturer in the Education Faculty, invited Arona Dison, the coordinator of the Centre, to involve the Centre in a project to strengthen the integration of academic literacies development within the curriculum of a B.Ed. Honours course. This involved employing writing centre tutors to give formative online feedback on writing tasks. The research forms part of a larger, design-based research (DBR) study undertaken by Karen. This article reports on two DBR cycles which focused on including tutor online support to enhance the development of academic writing and feedback literacies.

The research grew out of a critical need to improve the methods of formative feedback on academic writing of part-time B.Ed. Honours students. These students were unable to access the Centre during open hours due to their full-time work commitments. Historically, the Centre had provided assistance to undergraduate students while postgraduate students were referred to the Division of Postgraduate Studies. Honours students have tended to fall through this support network. Karen provided support in her module for the development of academic literacies through her task design, and through integrating explicit teaching about aspects of writing in her lectures. She built opportunities for scaffolding and feedback on four nested tasks which led to the writing of a final, summative assessment task. She introduced peer online feedback into her assessment strategy using Turnitin. In 2018, she included the provision of feedback by writing centre tutors in a systematic and structured way which was then integrated into the design of the formative assessment strategy.

Tutors received training by an online technology specialist on technical aspects of Turnitin, and by the lecturer and the Centre on the pedagogical dimensions of providing written and online feedback. This was informed by theory as well as data from the pilot iteration of the research in 2017 which highlighted which type of online comments students found most helpful. In addition, the lecturer inducted the tutors into the aims and expected outcomes of her semester course, as well as the assignment expectations, assessment rubrics, and the class feedback norms. Tutors were introduced to the class at the start of the course in 2018 in order for both the students and the tutors to meet one another so that a "human face" or a person behind the online relationship could be recognised.

Assignments and formative feedback were provided in Standard English, although students had the option to write their assignment task in one of three languages, as stipulated in the official 
UWC language policy. During the face-to-face lecture sessions with students, the lecturer would provide summary feedback on their writing development, and engage with student questions related to the assignment task and course theory. In class, students were given general feedback on both positive and negative trends in their academic writing which were being observed by peers, tutors, and the lecturer in the online environment. In addition, students were asked to provide feedback to the lecturer and tutors on the nature of the feedback comments they received, and how feedback could be improved. In their third online submission, students were asked to reflect on their writing tasks using the rubric criteria and task brief in order to identify areas for improvement. They were then to write a comment to their tutors that would elicit the specific feedback they required in order to enhance their own writing or thinking. The basis for the online, asynchronistic dialogue between tutor, student, and the lecturer was supported through weekly class meetings/lectures which sought to link writing, reading, and thinking to the assessment task brief. Thus, there was a blended learning dimension to the feedback strategy through combining online and face-to-face feedback, although the feedback provided directly by tutors was only through an online medium.

\section{Review of the literature}

\subsection{Academic literacies}

This study is informed by an academic literacies approach which views literacies as social practices embedded in socially- and culturally-situated contexts (Street 1984, Lea and Street 1998). Applying an understanding of literacies as social practice to higher education, theorists argue for a move away from a skills-based deficit model of student writing, which locates problems with individual students, and to consider the complexity of writing practices required at university (Ballard and Clanchy 1988, Lea and Street 1998). Learning in higher education is understood as involving new ways of knowing, interpreting, and organising knowledge, and it is deeply embedded within the ways that the "various disciplines construct themselves through language" (Jacobs 2007: 875). There is thus not one generic form of academic literacy, but rather many different literacies which are embedded in different social or disciplinary contexts (Lea and Street 1998). Furthermore, there are implicit academic writing conventions linked to disciplinary practices which students need to master. The term "academic conventions" refers here to "generally accepted discipline-specific rules of writing, such as use of the first person, structure, validity and use of evidence and rules of referencing" (Rai 2004: 151). As part of their acquisition of academic literacies, students are required to "switch practices between one setting and another, to deploy a repertoire of linguistic practices appropriate to each setting, and to handle the social meanings and identities that each evokes" (Lea and Street 1998: 159). Development of academic literacies is linked to the forming of a student's scholarly identity through their growing awareness of the discourse and disciplinary requirements of academic writing (Dison and Clarence 2017: 8).

In spite of a large body of research which points to the need for development of students' academic literacies within disciplinary contexts, the dominant models of literacies development at universities take place outside of disciplinary curricula. These include stand-alone "academic literacy" courses, and the dominant model of a decontextualised writing centre where students come for assistance outside of their disciplinary teaching-and-learning context. An academic literacies approach to students' development of academic reading and writing would imply that literacies are 'best taught by 'insiders' who have 'mastered the discourse' of that particular 
academic community" (Jacobs 2005: 477). These "insiders" have tacit knowledge and understanding of the workings of discourse within their disciplines. However, Jacobs argues that because of the tacit nature of their knowledge of disciplinary discourses and practices, they take this knowledge for granted. Therefore, an academic literacy specialist can play a valuable role as an "outsider" who collaborates with the disciplinary specialist to provide scaffolding for the students to acquire the required literacies (Jacobs 2005: 478). Jacobs' research supports an approach to development of students' academic literacies within disciplinary sites of learning. One of the most powerful ways of providing scaffolding for students' learning is through feedback on writing. Tacit knowledge of academic and disciplinary literacies needs to be made explicit and "taught" to students. Learning takes place through opportunities to practise these literacies, and feedback plays a crucial role in guiding students towards mastering them. In order to learn from feedback, students need to learn to "appreciate feedback messages, develop their capacities in making judgments and [be able to] make adjustments to their own work during its production" (Carless and Boud 2018). This capacity is referred to as "feedback literacy" (Sutton 2012, Carless and Boud 2018).

\subsection{Formative assessment, feedback literacy, and technology}

Meaningful assessment tasks, and appropriate and timely feedback that supports students' improvement of work are widely recognised in the literature as key to student learning and success (Boud and Molloy 2013). Feedback is the "mechanism through which students discover whether they are successful in their work and if they are on track to meet expectations" (Boud and Molloy 2013). However, literature on assessment in HEIs indicates that there is a tendency to provide summative feedback rather than increased opportunities for student learning through formative feedback (David, Nicol and Macfarlane-Dick 2006, Carless and Boud 2018). Furthermore, poor feedback processes and assessment opportunities increase levels of student dissatisfaction (Boud and Molloy 2013).

Feedback, according to Boud and Molloy (2013), can only be justified if it changes what students can do. They argue that there is a need to shift the focus on the delivery of feedback from teacher to students. This would include a focus on what happens "prior to teacher inputs - briefing, orientation, nature of the task - and what occurs afterwards - response of students, subsequent attempts at tasks or submission of work" (Boud and Molloy 2013: 2). Clarence (2011: 50) asserts that feedback "should be seen as a foundation upon which writing practices are explored through scaffolding". Feedback needs to inform students' ability in later life to "trust their self-evaluative capacity" (Boud and Molloy 2013: 3). In the context of higher education, self-reflective and judgmental competencies are essential in promoting and developing sustainable feedback literacies.

There is consensus in the literature about a need for improved systems of student feedback and assessment in HEIs. Clarence (2011: 50) contends that often feedback places students "on the periphery of their own writing". Rather, the type of formative feedback students receive should build their self-esteem and empower them (Skead and Twalo 2011). Clarence (2011) cautions against feedback which is judgmental and which discourages interaction.

While opportunities to receive feedback are crucial, equally important is students' feedback literacy, their receptivity to feedback, and their ability to respond to it (Sutton and Boud 2012, Boud and Molloy 2013, Carless and Boud 2018). Sutton (2012) defines "feedback literacy" as 
the ability to read, interpret, and use written feedback. Carless and Boud (2018: 2) extend this definition of "student feedback literacy" as the "understanding of what feedback is and how it can be managed effectively; capacities and dispositions to make productive use of feedback; and appreciation of the roles of teachers and themselves in these processes".

The use of online computer-assisted feedback is shown in the literature to support learner achievement effectively, and it has the potential to reduce workload in large classes (Hattie and Timperley 2007). Collett, van den Berg, Verster, and Bozalek (2018) found that technology used in a blended environment provided course participants with increased levels of feedback from peers and facilitators, keeping facilitators informed about the extent of student engagement. Boud and Molloy (2013: 20) promote the "nesting of tasks" to ensure that the feedback loop is completed, and the effects of earlier feedback can be traced. In the nesting of tasks, they recommend that there is a continuity in learning outcomes although the level of task complexity may increase.

When selecting e-learning tools to support effective learning, Bower (2008) recommends that an explicit approach is used. This requires a careful consideration of the technological affordances of the tools as well as the affordance needs of the e-learning task so that the learning process can be designed in a carefully scaffolded manner. While the inclusion of Information and Communication Technology (ICT) enhances the learning environment as it provides more opportunities for learning, it is advantageous to provide a blend of online and traditional practices (Uden and Beaumont 2006). A review of the literature on assessment reveals that technology can enable a level of feedback and support to students, where it is conceptualised within the broader aims of the assessment task and the overall design of the course (Boud and Molloy 2013). The use of online technology for formative feedback, and the role of writing centres have both received limited attention in the South African literature.

\subsection{Computer-assisted feedback using Turnitin}

In this study, the affordances of Turnitin were used to enhance students' formative online feedback and academic feedback literacies. Turnitin is an anti-plagiarism programme which is used for similarity checks where students' writing is checked for matches with other sources and rated in terms of level of similarity. However, Sutherland-Smith and Carr (2005) caution that Turnitin is not effective as anti-plagiarism software without the review, checking, and editing by staff and students. In this intervention, the similarity check as well as peer feedback affordances of Turnitin were used to provide formative online feedback to students by tutors. Turnitin's similarity and feedback affordances provide a range of written and audio cues through which tutors can provide formative feedback using a chosen language preference. Furthermore, the identity of the person giving feedback can be anonymous or made known. These affordances of Turnitin enable a flexible range of social and cognitive engagement options to mediate learning. A preliminary review of the literature related to the peer feedback and grading features of Turnitin did not yield any significant results other than comments on the Turnitin website that cited lecturers identifying positive features of its verbal and audio feedback features.

\section{Methodology}

A social constructivist epistemology congruent with the research aims and methodology of DBR inform this study. A DBR approach aims to provide improved solutions to practical 
problems, in this case, the improvement of formative feedback to students in order to develop their academic writing. Wang and Hannafin (2005: 6-7) define DBR as:

a systematic but flexible methodology aimed to improve educational practices through iterative analysis, design, development, and implementation, based on collaboration among researchers and practitioners in real-world settings and leading to contextually-sensitive design principles and theories.

In keeping with the principles of DBR, both the successes and failures of this intervention are tracked and reflected on as they relate to the key concepts of 'place', 'space', and 'power'. Research ethics permission to conduct this study was obtained through UWC's Human and Social Science Research Ethics Committee (No. HS/16/6/26).

In 2018, two iterations of the innovation were conducted in the first and second semesters, respectively. Data was collected by means of anonymous online pre- and post-course student surveys. In addition, semi-structured individual interviews were conducted with five students in the first iteration, and a focus group interview of three students took place in the second iteration. Meetings of the lecturer, coordinator, and tutors to reflect on the first and second iterations were audio-recorded and used as data (COPX meetings 1 and 2). Furthermore, the data consisted of the lecturer's field notes as well as notes from a reflective dialogue between the lecturer and coordinator.

Data analysis was informed by the DBR approach. This involved the extraction of principles from the literature and practice which were used to inform the design of the initial iteration. This was followed by the preliminary testing of the design, and the refinement of principles in the second iteration in relation to theory and learning from practice. Data collection and analysis occurred iteratively throughout the study, and were flexibly related to needs of the research process. Data was analysed using a grounded theory approach (Glaser and Strauss 1967). Consistent with a DBR approach, key principles were formulated based on the analysis of the data.

\section{Findings and discussion}

Dison and Clarence (2017: 15) articulate the view that writing centres will need to "increasingly venture beyond their four walls into other spaces - within and across the disciplines - to challenge their own pedagogical approaches and those of others". In this article, we explore this vision through the metaphor of decentering and recentering the work of the writing centre. We do this in relation to our innovation of integrating academic literacies development of students through formative online feedback within a B.Ed. Honours module. We use the organising concepts of 'place', 'space', and 'power' to explore a number of key themes from the data in relation to current literature on the role of writing centres in the development of academic literacies.

\subsection{Place}

Two key themes emerged from our findings in relation to place. Firstly, a decentering of the physical space of the Centre in relation to the strategic direction of moving out into working with departments in an integrated way; secondly, a decentering or moving out of the physical place of the Centre to the virtual, online space. 
Many writing centres in South Africa have extended their work into disciplinary collaborations and partnerships informed by an academic literacies approach. Furthermore, these writing centres have begun to make inroads into disciplinary assessment practices (Dison and Clarence 2017: 14). Firstly, we see the integration of the work of the Centre into the Education module curriculum and assessment strategy as a move to decentre the literacies development work from the physical place of the Centre to the site of collaboration and dialogical feedback in the Education module. Decentering took place through a collaborative partnership between the lecturer, the Centre coordinator, and the tutors, where the lecturer was able to draw on these persons' expertise. In addition, the tutors played a key role in providing online feedback to students as well as engaging with the lecturer and coordinator in a dialogical community of praxis.

Secondly, decentering took place as a result of the inclusion of online technology in formative assessment. The work of the Centre was decentred through a shift from face-to-face consultations in the physical writing centre space to a virtual, online model of interaction through the tutors' contribution to online feedback on students' writing. The tutors and the lecturer were all able to view a student's work and their feedback comments. This online engagement around feedback on student writing informed face-to-face meetings between the lecturer, the Centre coordinator, and the group of tutors. In her reflective dialogue, Karen commented on the decentering from the Centre place to the online space:

[...] we can meet anywhere but what is holding us together is the online space and the way that the curriculum and assessment strategy is constructed. I am not looking at the curriculum as just content but as an enacted curriculum. Tutors are linked right into the course. They are not just hanging around [...] contact with them is built into the design and takes place over a sustained period of time for all students.

The use of technology enabled students to receive formative feedback from the Centre despite being unable to come and consult within office hours. Turnitin was used to make feedback more immediate and accessible for students and tutors. In her reflective dialogue, Karen pointed out that there is often "a separation between the feedback the lecturer gives and the feedback the tutor gives. Now with technology the feedback is given all in one 'place' which is the document. This is where the collaboration is taking place".

While arguing for the need for decentering and recentering of the work of writing centres, we are not questioning the value of a writing centre which is housed in a physical place within an institution with its own organisational infrastructure. A writing centre provides an important liminal and safe space (Archer and Richards 2011), and a "free" space (Nichols 2017) for students and tutors to meet in an institutional environment that can be alienating and restricting for students. Harris (1992) argues that a writing centre provides "a focal point, a place for writing on campus [...] where writers write, where they talk, [where] collaboration is a normal part of writing and [where] writers really do write for readers" (Harris 1992: 157158, in Clarence 2011: 106).

Writing centres strive to provide a welcoming, supportive environment where students can engage in dialogue with tutors about their writing (Archer and Richards 2011). While students in this case study were not able to use the services of the Centre as a physical place, they found the tutor engagement and support invaluable. However, both students and tutors missed the opportunity for face-to-face interaction. A student commented that she would like "one-on-one 
sessions with the relevant person" (student questionnaire). However, time would need to be allocated for this as well as a place to accommodate part-time postgraduate Honours students.

Tutors also commented on the strengths and weaknesses of online and written feedback which shaped and constrained the role they could play in systematically guiding students through dialogical engagement. Thabo observed that he "enjoyed [...] giving those comments because it gave me time to reflect and think and just go back and edit what I wrote". However, he was concerned that "you can't really follow up on nonverbal cues from a student. You don't know whether they are getting what you are saying, because they don't give their feedback to what we wrote" (COPX meeting 1). All tutors agreed that a combination of online and face-to-face feedback would be ideal.

While Turnitin's online feedback technology may have a number of advantages in enabling access for students, and providing them with a level of support and feedback, it was unable to simulate a synchronous dialogue between tutor and student, and the affective conditions that this can provide. Tutors were concerned about how students would respond to feedback given in an online environment where there were no affective cues and language to go on. Lizwe said, "I worried about when I was giving feedback. How did they feel in terms of the language? Was it soft, was it harsh, was it something like they were being commanded? Were they able to interpret the suggestions and the comments?" (COPX meeting 2).

We identified a need for an affective space for tutors to meet with students and engage in deepened dialogue both individually and collectively. The lecturer commented that she needed to build in "time for you as tutors to meet with people individually in your group, for them to come around, and then to speak about how they're finding the feedback, incorporating the feedback, are they understanding the comments you're making?" (COPX meeting 1).

The online environment did not provide a dialogical setting within which the tutor could ask probing questions to assist the student " [...] to find and communicate her thoughts, eventually [internalising] the questions of a reader so that she becomes independent" (Nichols 2011: 95). Thus, without the face-to-face consultations with tutors, there is a risk of falling back into the role of giving tips or asking a few probing questions which are unlikely to be discussed. This highlights the need for a safe and supportive physical place where students can meet with tutors for one-on-one dialogue in addition to online interaction.

Archer and Richards (2011: 9) see writing centres occupying a liminal space on the margins of the institution "to which members of a group withdraw and redefine their identities before reemerging in society to play a new role". At UWC, the Centre provides a safe space for tutors to develop a sense of identity as staff of the Centre, while they may be fairly marginalised as postgraduate students in their own disciplinary departments. Through their training, development, and experience at the Centre, they develop an additional dimension to their academic identities which incorporates a level of meta-knowledge about academic writing and the capacity to enhance other students' academic engagement.

In our reflections, Karen observed that, as a lecturer, she had found the Centre to be a supportive place that she could go to outside of her department and faculty in order to think through her curriculum design and the integration of academic literacies development. 
It's a place I can go to focus on an aspect of my practice such as assessment and feedback. I can highlight current challenges, engage with current theory, and get critical feedback. The conversations give me the invigorating energy I need to take this innovation further.

Both a decentering and a recentering of the Centre, with an expanded role in relation to consultation with lecturers and the integration of academic writing and feedback literacies, need to be considered to enhance access and collaboration. For the Centre coordinator, having a physical centre was important as it provides an institutional base from which to build collaboration with faculties and other academic support facilities. However, she recognised that "administrative systems have to shift from a very structured, schedule-bound system to a more flexible one". Furthermore "a more lateral way of thinking [was] needed to accommodate different modes of collaboration".

At an institutional level, having a physical centre gives a home to the strategic approach of integrating academic literacies. It provides the expertise and knowledge for training and development of tutors as well as a place to which lecturers can come for support in the integration of academic writing and feedback literacies in their course design and delivery.

\subsection{Space}

The concepts of 'place', 'space', and 'power' are closely connected in relation to the enabling of student, tutor, and lecturer academic and feedback literacies. In this discussion, we see 'place' as a physical space which flows over into 'space'. We use the term "space" in a figurative sense. The innovation in our study generated a space for the development of collaborative communities of praxis as a result of the closer integration of writing tutors into the online feedback practices in the course module. It also opened a space and modelled a practice in which Turnitin could be used developmentally, thereby challenging dominant institutional practices of using Turnitin as an anti-plagiarism device.

Building online formative feedback into the curriculum and assessment design facilitated the integration of the work of the Centre into the online classroom as one community of praxis, and into "the lecturer's office" with tutors as another community of praxis. This situated and contextualised approach to learning drew on the work of Lave and Wenger (1991) who argue that learning takes place through social mediation in a "community of practice". A learning community, or "community of practice", is based on a common passion or shared interest negotiated by the group members.

Dison and Clarence (2017: 7) refer to the induction of students into disciplinary communities of practice as follows:

[Students need] to become literate in creating and utilising [...] texts, and join the community of practice as legitimate participants, students need to be socialised into the community, and into the particular as well as more general rules their community follows in creating, consuming and critiquing knowledge.

Burke (2018: 16) defines a "community of praxis" as "the bringing together of critical reflection and action [which] is crucial in creating [...] transformative possibilities". Furthermore, practice 
in dialogue with research needs to be developed "to ensure that [...] taken-for-granted meanings that unwittingly perpetuate inequalities are challenged and eradicated at both the individual and institutional levels" (Burke 2018: 16). An aspect that was added to the face-to-face and online communities of practice was the engagement with theory related to course content and feedback literacy which nourished the development of communities of praxis. The communities of praxis involving students, tutors, and the lecturer enhanced an academic literacies approach to enable "students to respond to assessment and learning tasks with appropriate forms of research, reading, and writing" (Dison and Clarence 2015: 7-8). The class community of praxis was enabled both in the face-to-face contact as well as the online environment through sustained peer and collegial relationships and practices. Sustained learning within this socio-cultural, blended environment was focused on both content and process knowledge. The practices of this community included a common purpose and way of working together to make meaning both of the course content as well as developing students' academic literacies and feedback literacy. Socialisation into this community of praxis required students to engage with class norms as well as norms for giving and receiving feedback in the online environment. In addition, students were being socialised into the genres of writing and communicating used in the social science discipline of leadership and management as they read and analysed related articles.

The approach opened spaces for dialogical engagement between parties concerned - both the online and face-to-face space for collaborative communities of praxis. The focus was on building of skills, knowledge, and insight into the value of formative feedback, and how it is enhanced through collaboration using a blended learning and support approach. It required the building of relational and affective sensitivity in online spaces as well as language sensitivity. This included how feedback was elicited and given by all parties, as well as what languages were used to give formative feedback in order to enhance both the giving and uptake of this feedback.

Online feedback through Turnitin built a connective space for social cohesion that enabled students to engage with each other's writing. It reinforced the creation of an environment which promoted the building of collaborative learning and trust, which Liu and Carless (2006) argue is key to cultivating an environment to promote successful feedback. Liu and Carless (2006) argue for the importance of extending learning from the individual to the public domain through feedback. They contend that "one important way we learn is through expressing and articulating to others what we know or understand" (Liu and Carless 2006: 281). Karen commented that "[students were] going in and reading each other's work through Turnitin. They were getting ideas, picking up tips and seeing how people reference, seeing how they write [...] learning because they're part of that community". Their online participation in the community of praxis encouraged them to engage more with fellow students in the classroom or through communication tools such as WhatsApp to ask each other for feedback or discuss their writing. In an individual interview, Meg, one of the students, commented:

[...] because now we are more open because if it wasn't for that, we would have just individually submitted our assignments, and we won't know whether we are on the right path or not. But now by exposing and opening the channels, it's an additional help for us as students.

The lecturer found that the community of praxis helped her to meet with the writing tutors and the Centre coordinator in a sustained way to reflect critically on student engagement with the assessment task and formative feedback. She found the "community" helped her to test out her 
assumptions, and to reflect critically on theories informing her practice. She made this comment: "[It] provided me with a semi-autonomous space within which I could test out and get immediate feedback on my practice from a group of critical friends who all have a common interest in developing students' academic writing". Dialogue in the community of praxis provided the lecturer with insight into where she needed to support students better, review the design of her assessment tasks or give further input related to their academic writing and reading.

The importance for me of being able to link with you as tutors, to have the space to say, "This is what I'm doing", "This is what I'm looking for", to have that conversation happening is really useful, and then to find out what are the things you give feedback on, how do you do it, and that we're kind of clear on, like what does one expect in a critical essay, or a reflective essay - you know? [...] (COPX meeting 2)

For this community of praxis to develop, it required the lecturer to open up the space for engagement and critique of her practice to the tutors and the Centre coordinator. For writing centres generally, building reciprocal collaborative working relationships with lecturers is often a challenge (Esambe and Mkonto 2017). In a reflective dialogue, the coordinator commented:

Most lecturers see the Centre as a one-way communication when they come and brief us, where they tell us what they require of us and what the assignment is about $[\ldots]$ it feels uncomfortable to give feedback on the assessment task because that is not part of the brief. Their sense of the Centre is that it provides a service and helps students to improve their writing and to help students to meet their requirements. But the lecturer's own assessment tasks are not up for scrutiny. In most cases lecturers do not come to us but we see the students. We get the assignment topic and it is decontextualised and that is it.

The innovation with a sustained community of praxis opened up the space for the Centre staff to engage in dialogue with the lecturer on her assessment task and formative feedback strategy. The Centre coordinator commented in her reflective dialogue that the process of engagement shifted the usual power dynamics:

The way we were working together, there were less power differentials in giving [the lecturer] feedback as the tutors had a voice in giving you feedback and you were giving them space to [do so] and taking their feedback seriously.

For tutors, being involved in an online and face-to-face community of praxis helped open up their feedback practices to colleagues and the lecturer, as well as helping to develop their own feedback literacies in an online space. Tutors were also able to get exposure to current theories of feedback and assessment from the lecturer, and engage in dialogue about what processes enhanced feedback uptake. For the Centre coordinator, the online experience of tutors giving feedback helped to build tutor capacity for face-to-face feedback. She commented that developing experience in giving online feedback helped to build their capacity as writing tutors generally. She remarked in a reflective dialogue that "to give feedback that is written (online) requires a lot of skilled attention to grasp what the main issues are and this develops their capacity to give face-to-face feedback". 
Developing these communities of praxis with a focus on the development of feedback and academic literacies has the potential to enhance social justice pedagogy if there is a commitment from lecturers to open up their practice to scrutiny. However, creating opportunities for such communities of praxis to exist on campus can be a challenge as they demand time and trust. Much depends of the openness of lecturers to engage in collaborative practices with the centre related to the development of academic and feedback literacies within their course or programme curriculum. Skead and Twalo (2011: 128) argue that:

[...] teaching staff need to reflect on the extent to which students are empowered to develop their own identities as learners and writers who learn through writing and make sense of the conventions of academic discourse through process writing. Such reflections could address the enormous challenges surrounding the development of independent, successful learners.

These communities of praxis provided a contextualised space for meaning making and the development of the tutors, lecturer, and the coordinator. Tutors gained insight into disciplinary literacies through being part of these communities of praxis. All participants were learners and teachers in this space, developing their academic writing and feedback literacies, and informing curriculum development of the module. While an integrated model is labour intensive, as pointed out by Skead and Twalo (2011), it holds the potential for transformative practice.

This innovation was made possible by the lecturer's openness to engage with and explore academic literacies, and particularly the development of feedback literacies. The coordinator felt that, while it did not necessarily make for a replicable model, it provided a strategy which could be adapted for different contexts where appropriate. She stated that "[there] is not enough collaborative work of this kind that is happening and not many lecturers would be prepared to take this risk of doing something new. It requires more effort from them to take tutors that are inexperienced and from different disciplinary backgrounds and to trust they will be able to make a contribution in their modules".

\subsection{Power}

Three key aspects are engaged with in relation to power. Firstly, the marginalisation of the Centre in relation to the core learning and teaching functions of departments; secondly, the empowerment of tutors and students through the development of their academic and feedback literacies, and, thirdly, the role of technology in supporting student academic and feedback literacies.

We have discussed the tendency for writing centres, including the Centre at UWC, to be marginalised in relation to the core learning and teaching functions of departments and faculties. They tend to be marginalised in relation to power structures in the university, and operate with few resources and few permanent academic staff which challenges their capacity and agency to contribute to institutional change. The collaborative innovation between the Centre and the lecturer in relation to the B.Ed. Honours module was an example of a small scale intervention in which the Centre was able to apply the principles of integration of academic literacies to which it aspires.

Writing centres' engagement with students' learning tends to have limitations because of their marginal space outside of disciplinary sites of learning. This is exacerbated in the case of small 
writing centres like the Centre at UWC that services all the faculties on campus. Some lecturers brief the tutors about the requirements for an assignment. In some cases, tutors can give generic feedback to students. In their training, they are made aware of the existence of different genres and conventions, and there is a clear directive that they should not impose their own disciplinary conventions on other disciplines. Instead, they should find out what they can about the appropriate requirements, both from the student and other sources, and be tentative in their advice.

An integrated approach to the development of students' academic literacies recognises that students need to master discipline-specific "norms, values and conventions for reading and writing" (Jacobs 2005: 485). Educational leadership and management is an applied, interdisciplinary field. As mentioned, the students are practicing professionals in schools. The lecturer takes an inquiry-led approach to learning, requiring the students to gather information and engage with colleagues in their own professional contexts. Students are required to reflect on this inquiry-generated data, relating it to theory, and locating their discussion in relation to historical and current policy. Furthermore, the students are expected to develop their own argument based on evidence, and analyse and critique arguments. Thus, they need to engage in complex literacy practices.

In order to give effective feedback in this intervention, tutors needed to gain insight into the literacies required through briefing from the lecturer, discussions in meetings with the lecturer and Centre coordinator, and their own careful and attentive reading of the assignment instructions and reflection on students' writing. While their feedback did not focus on content, they did need to give the students guidance on the literacies required.

Engaging with feedback and building feedback literacies helped to empower the tutors, students, and the lecturer. In this intervention, the focus on giving and the uptake of feedback became the centre of dialogue and reflection in the community of praxis in the class and between the tutors, lecturer, and Centre coordinator. This focus helped to build agency for and awareness of improving feedback processes, and a growing understanding of feedback and how it could be provided most constructively was built amongst all parties. Both students and tutors were sensitised to language use when giving and eliciting feedback. They also reflected on how the experience of giving and receiving feedback built their capacity as students, educators, and tutors. Tutors felt that the affordances of Turnitin enhanced feedback as "[student] progress can be easily monitored [through] consistent back-to-back feedback" (previous assignments are automatically saved, and the tutor can always go back to compare). Furthermore, the tutors commented that "students are able to reflect [on] and identify the areas they need help with, which enables them to take responsibility for their learning". This helped the tutors to have a clear focus area when providing guidance.

Students were asked to reflect on the type of feedback they needed for tasks, which enabled the lecturer and tutors to be more directed when engaging with their writing. In a draft of the final summative submission, a student commented: "Can tutors or you please look at the structure of my final draft - logic and structure?" (S1, 2018). Another student asked for a range of feedback on both the content and technical aspects of her writing. She asked the lecturer to give "references that will assist me [and give] feedback on referencing". She asked, "How can I look at things in a different way? [...] Which parts should I delete in order to shorten the essay?". Students were playing a constructive role in shaping how they wanted feedback to be given as well as building their awareness of the value of feedback in formative assessment processes. 
The tutors' involvement in the online feedback intervention provided the space to build their confidence and expand their professional practice. It also built their confidence to engage with lecturers and contribute to improved curriculum design as a result of their insight into student experience. They were able to voice concerns about students' needs, and played an active role in suggesting how assessment tasks or pacing of tasks could be improved. This shifted traditional power dynamics in the curriculum design process from a lecturer-centred one to a collective process. This practice holds the potential for increased student participation in curriculum transformation, and demonstrates one of the ways in which writing centres can give students a "voice in the conversations on their campuses about proposed changes to assessment, evaluation, curriculum and pedagogy that are currently taking place in a range of fora" (Dison and Clarence 2017: 14).

Being part of the communities of praxis empowered the tutors by developing their feedback literacies which they could use in other contexts. The Centre coordinator made the following comment in a reflective dialogue:

Tutors are developing in a number of ways through practice, firstly through giving written feedback and having to be carefully attentive. Then they are also exposed to the assessment strategy of the lecturer and they are playing a role in giving feedback to students on their processes of development in relation to the assignment. They are also playing another role in giving feedback to the lecturer on how the students are managing and what needs to be improved in the support for students.

Capacity building of tutors through engagement in a sustained community of praxis supported a transformative agenda in rendering them capable of expanding their professional practice and building their confidence to engage with lecturers. They were able to address challenges at the level of assessment or task design with the lecturer in relation to student feedback. This expanded their role from guide and consultant to students, to engaging with the lecturer as a "critical friend". For example, in a discussion about some of the students' lack of engagement with feedback, Rasheeqa, one of the tutors, gave the suggestion to provide "more gaps between the hand-ins so that they actually have time to reflect on the feedback before the following assignment is due [...] or for them to actually reply to the feedback so that you know they've actually engaged with it".

This innovation was enabled through the use of technology in supporting student formative feedback. Using an online platform such as Turnitin has the potential to increase opportunities for feedback on academic writing for students. However, it also holds the potential to silence their voice if face-to-face spaces are not created in which students can develop their voice and access the necessary technology. The use of Turnitin did not enable an online dialogue between student and tutor to take place simultaneously. While online feedback can put the student at the centre of the interaction between tutor, student, and lecturer, it was found to have the power to intimidate and silence the student if there was little mediation of feedback in class or opportunities for tutor face-to-face engagement to follow up on feedback uptake. Disempowerment of students increased if technological skills were limited, if they could not afford access to the internet off campus, if the pacing of tasks was too quick, or if the language of feedback was discouraging and difficult to understand. 


\section{Conclusion}

Our article has reflected on the role played by the UWC Writing Centre in an intervention where the space of engagement with students moved from the face-to-face, physical writing centre location to the online space. It has explored the potential, limitations, and challenges of this approach as one of the ways in which the Centre can work with lecturers to integrate academic literacies into the curriculum.

Our findings point to the need for both a decentering and recentering of the role of writing centres within the context of a digital age and policy promoting formative assessment, and the integration of academic literacies within course curricula. These shifts require the Centre to consider more flexible and blended approaches to providing student support, as well as taking on a greater role in supporting lecturers and departments in the integration of academic literacies into curriculum design and support. This article has explored how the Centre has been able to expand its role beyond its "four walls" through the use of a technology-enhanced blended learning approach to support the development of academic literacies. Central to this has been the building of collaborative relationships, and a way of working in supportive communities of praxis of students, writing centre staff, and lecturer through which academic and feedback literacies were developed. The contribution of the writing centre was firmly located in the curriculum and assessment space. This involved the decentering of writing centre practice in relation to place, space, and power, and a recentering within the disciplinary curriculum context through a collaborative model of developing academic literacies.

\section{References}

Archer, A. and R. Richards. 2011. Writing centres as alternate pedagogical spaces. In A. Archer and R. Richards (eds.) Changing spaces: Writing centres and access to higher education. Stellenbosch: Sun Press. pp. 5-15.

Ballard, B. and J. Clanchy. 1988. Literacy in the university: An 'anthropological' approach. In G. Taylor, B. Ballard, V. Beaseley, H. Bock, J. Clanchy and P. Nightingale (eds.) Literacy by degrees. Milton Keynes: SRHE and Open University Press. pp. 7-23.

Barrie, S. 2007. A conceptual framework for the teaching and learning of generic graduate attributes. Studies in Higher Education 32(4): 439-458. https://doi.org/10.1080/0307507070 $\underline{1476100}$

Boud, D. and E. Molloy. 2013. Feedback in higher and professional education: Understanding it and doing it well. London: Routledge.

Bower, M. 2008. Affordance analysis - Matching learning tasks with learning technologies. Educational Media International 45(1): 3-15. https://doi.org/10.1080/09523980701847115

Bozalek, V. and A. Dison. 2013. Using the human capabilities approach as a normative framework to evaluate institutional teaching and learning interventions at UWC. South African Journal of Higher Education 27(2): 383-400. https://doi.org/10.20853/27-2-248 
Burke, P.J. 2018. Re/imagining widening participation: A praxis-based framework. University of Newcastle, Australia: English Language and Foundation Studies Centre and the Centre of Excellence for Equity in Higher Education.

Carless, D. and D. Boud. 2018. The development of student feedback literacy: Enabling uptake of feedback. Assessment and Evaluation in Education 43(8): 1315-1325. https://doi.org/10. $\underline{1080 / 02602938.2018 .1463354}$

Clarence, S. 2011. Writing in the academy: Collaborative writing development with students and lecturers at the UWC Writing Centre. In A. Archer and R. Richards (eds.) Changing spaces: Writing centres and access to higher education. Stellenbosch: Sun Press. pp. 101-114.

Collett, K.S., C. van den Berg, B. Verster and V. Bozalek. 2018. Incubating a slow pedagogy in professional academic development: An ethics of care perspective. South African Journal of Higher Education 32(6): 117-136. https://doi.org/10.20853/32-6-2755

D'Andrea, V.M. and D. Gosling. 2005. Improving teaching and learning: A whole institution approach. Maidenhead: SRHE and Open University Press.

Dison, L. and S. Clarence. 2017. Introduction. In S. Clarence and L. Dison (eds.) Writing centres in higher education: Working in and across the disciplines. Stellenbosch: Sun Press. pp. 5-16. https://doi.org/10.18820/9781928357551

Esambe, E.E. and N. Mkonto. 2017. Negotiating writing centre practices within and between disciplines in a university of technology. In S. Clarence and L. Dison (eds.) Writing centres in higher education: Working in and across the disciplines. Stellenbosch: Sun Press. pp. 113-127. https://doi.org/10.18820/9781928357551

Glaser, B.G. and A.L. Strauss. 1967. The discovery of grounded theory: Strategies for qualitative research. Chicago, IL: Aldine Publishing Co.

Harris, M. 1992. The writing center and tutoring in WAC programs. In S.H. McLeod and M. Soven (eds.) Writing across the curriculum: A guide to developing programs. London: Sage Publications. pp. 154-170.

Hattie, J. and H. Timperley. 2007. The power of feedback. Review of Educational Research 77(1): 81-112. https://doi.org/10.3102/003465430298487

Jacobs, C. 2005. On being an insider on the outside: New spaces for integrating academic literacies. Teaching in Higher Education 10(4): 475-487. https://doi.org/10.1080/13562510 $\underline{500239091}$

Jacobs, C. 2007. Mainstreaming academic literacy teaching: Implications for how academic development understands its work in higher education. South African Journal of Higher Education 21(7): 870-881. https://doi.org/10.4314/sajhe.v21i7.25748

Lave, J. and E.W. Wenger. 1991. Situated learning: Legitimate peripheral participation. Cambridge: Cambridge University Press. https://doi.org/10.1017/cbo9780511815355.003 
Lea, M. and B. Street. 1998. Student writing in higher education: An academic literacies approach. Studies in Higher Education 23(2): 157-172. https://doi.org/10.1080/030750 $\underline{79812331380364}$

Leibowitz, B., K. Goodman, P. Hannon and A. Parkerson. 1997. The role of a writing centre in increasing access to academic discourse in a multilingual university. Teaching in Higher Education 2(1): 5-19. https://doi.org/10.1080/1356251970020101

Liu, N. and D. Carless. 2006. Peer feedback: The learning element of peer assessment. Teaching in Higher Education 11(3): 279-290. https://doi.org/10.1080/13562510600680582

Morrow, W.E. 2009. Bounds of democracy: Epistemological access in higher education. Pretoria: HSRC.

Nichols, P. 2017. Writing democracy: From writing centres to writing fellows to writing intensive courses in a university-wide writing programme. In S. Clarence and L. Dison (eds.) Writing centres in higher education. Working in and across the disciplines. Stellenbosch: Sun Press. pp. 35-47. https://doi.org/10.18820/9781928357551

Nicol, D.J. and D. Macfarlane-Dick. 2006. Formative assessment and self-regulated learning: A model and seven principles of good feedback practice. Studies in Higher Education 31(2): 199-218. https://doi.org/10.1080/03075070600572090

Rai, L. 2004. Exploring literacy in social work education: A social practices approach to student writing. Social Work Education 23(2): 149-162. https://doi.org/10.1080/0261547042000 $\underline{209170}$

Scott, I. and G. Omar. 2016. "Fees in Higher Education" address to the UWC staff forum. (Personal notes, K. Collett, 2016).

Skead, M. and T. Twalo. 2011. An integrated collaborative model for writing and language advancement. In A. Archer and R. Richards (eds.) Changing spaces: Writing centres and access to higher education. Stellenbosch: Sun Press. pp. 115-130.

Street, B.V. 1984. Literacy in theory and practice. Cambridge: Cambridge University Press.

Sutherland-Smith, W. and R. Carr. 2005. Turnitin.com: Teachers' perspectives of antiplagiarism software in raising issues of educational integrity. Journal of University Teaching \& Learning Practice 2(3): 94-101.

Sutton, P. 2012. Conceptualising feedback literacy: Knowing, being, and acting. Innovations in Education and Teaching International 49(1): 31-40. https://doi.org/10.1080/14703297.2012. $\underline{647781}$

Uden. L. and C. Beaumont. 2006. Technology and problem-based learning. London: Information Science Publishing.

University of the Western Cape. 2012. Assessment policy. Bellville: University of the Western Cape. 
University of the Western Cape. 2015. Institutional operating plan 2016-2020. Bellville: University of the Western Cape.

UWC Directorate of Teaching and Learning. 2010. Final integrated graduate attributes \& teaching and learning strategic plan. Bellville: University of the Western Cape.

Wang, F. and M.J. Hannafin. 2005. Technology-enhanced learning environments. Educational Technology Research \& Development 53(4): 5-23. 